\title{
New evidence links periodontitis with hypertension
}

People with periodontitis have a greater likelihood of high blood pressure (hypertension), according to a new study. ${ }^{1}$

Author Professor Francesco D'Aiuto of UCL Eastman Dental Institute said: 'The more severe periodontitis is, the higher the probability of hypertension. The findings suggest that patients with gum disease should be informed of their risk and given advice on lifestyle changes to prevent high blood pressure.'

High blood pressure affects $30-45 \%$ of adults and is the leading global cause of premature death, ${ }^{2}$ while periodontitis affects more than $50 \%$ of the world's population.

Hypertension is the main preventable cause of cardiovascular disease, and periodontitis has been linked with increased risk of heart attack and stroke.

'Hypertension could be the driver of heart attack and stroke in patients with periodontitis,' said Professor D’Aiuto. 'Previous research suggests a connection between periodontitis and hypertension and that dental treatment might improve blood pressure, but to date the findings are inconclusive.'

This study compiled the best available evidence to examine the odds of high blood pressure in patients with moderate and severe gum disease. Moderate-to-severe periodontitis was associated with a $22 \%$ raised risk for hypertension, while severe periodontitis was linked with $49 \%$ higher odds of hypertension.

Average arterial blood pressure was higher in patients with periodontitis compared to those without. This amounted to $4.5 \mathrm{mmHg}$ higher systolic and $2 \mathrm{mmHg}$ higher diastolic blood pressures. An average $5 \mathrm{mmHg}$ blood pressure rise would be linked to a $25 \%$

increased risk of death from heart attack or stroke.'

Just five out of 12 interventional studies included in the review showed a reduction in blood pressure following gum treatment.
The changes occurred even in people with healthy blood pressure levels.

Professor D'Aiuto said: 'The evidence suggesting periodontal therapy could reduce blood pressure remains inconclusive. In nearly all intervention studies, blood pressure was not the primary outcome. Randomised trials are needed to determine the impact of periodontal therapy on blood pressure.'

He noted that the study investigated gum disease as a potential risk factor for hypertension, but the reverse could also be true, and recommended providing oral health advice to those with hypertension.

\section{References}

1. Aguilera E M, Suvan J, Buti J et al. Periodontitis is associated with hypertension: a systematic review and meta-analysis. Cardiovasc Res 24 September 2019 Available at: https://academic.oup.com/cardiovascres/ article-lookup/doi/10.1093/cvr/cvz201 (accessed September 2019).

2. Williams B, Mancia G, Spiering W et al. 2018 ESC/ESH Guidelines for the management of arterial hypertension. Eur Heart J 2018; 39: 3021-3104.

\section{Here has been an advertisement.}

